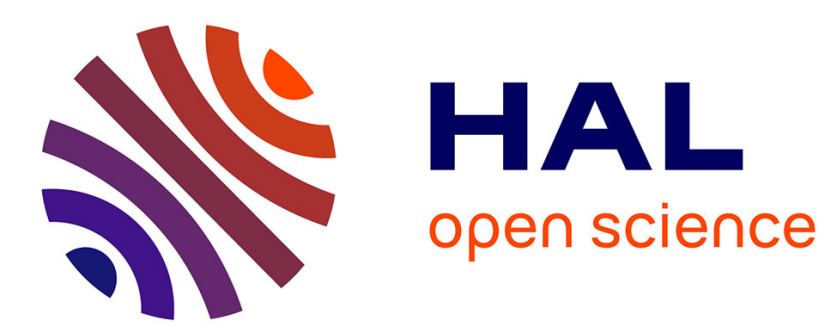

\title{
The instrumental deconstruction as a link between drawing and geometrical figure
}

Joris Mithalal, Nicolas Balacheff

\section{To cite this version:}

Joris Mithalal, Nicolas Balacheff. The instrumental deconstruction as a link between drawing and geometrical figure. Educational Studies in Mathematics, 2018, 10.1007/s10649-018-9862-z] . hal01950391

\section{HAL Id: hal-01950391 \\ https://hal.science/hal-01950391}

Submitted on 10 Dec 2018

HAL is a multi-disciplinary open access archive for the deposit and dissemination of scientific research documents, whether they are published or not. The documents may come from teaching and research institutions in France or abroad, or from public or private research centers.
L'archive ouverte pluridisciplinaire HAL, est destinée au dépôt et à la diffusion de documents scientifiques de niveau recherche, publiés ou non, émanant des établissements d'enseignement et de recherche français ou étrangers, des laboratoires publics ou privés. 


\title{
THE INSTRUMENTAL DECONSTRUCTION AS A LINK BETWEEN DRAWING AND GEOMETRICAL FIGURE
}

\author{
Joris Mithalal ${ }^{1}$, Nicolas Balacheff ${ }^{2}$
}

Authors tapuscrit of: Mithalal J., Balacheff N. (2018) The instrumental deconstruction as a link between drawing and geometrical figure. Educational Studies in Mathematics. [https://doi.org/10.1007/s10649-018-9862-z]

\begin{abstract}
In this article we examine how it is possible, in the teaching and learning of geometry, to bridge the gap between problems involving drawings and figures, which is essential to the learning of mathematical proof. More precisely, the way students' drawings perception has to evolve, from Iconic Visualization to Non-Iconic Visualization (Duval, 2005). We show that the Instrumental Deconstruction process is multifaceted and central in this evolution. We present a theoretical framework, in relation with an experiment based on a 3D Dynamic Geometry Environment. Based on a case study, we show that construction tasks with specific representations make the instrumental work play a key role in the learning of geometry.
\end{abstract}

Key words: deductive geometry, 3D dynamic geometry, instrumental deconstruction, drawings

\section{INTRODUCTION}

Drawings play a central role in the learning of geometry but they more often than not turn into an obstacle to the learning of mathematical proof: seeing results in a diagram leads student to question the need to prove "mathematically". For instance, Jahnke (2007, p. 79) noted that "in an empirical study covering ca. 3000 British high achieving students of grades 8 and 9, more than 50\% chose a 'pragmatic argument' as warranty for the angle sum theorem for triangles".

We explored the reasons for this tension between "seeing on a drawing" and proving (Mithalal, 2010). One outcome of this research supports the claim that 3D Dynamic Geometry Environments (DGEs) could provide a way to reduce this tension: deductive geometry is needed to perform certain kind of constructions, hence mathematical proof and construction tasks turn to be connected.

In this article, we report how these tasks may help the students use of deductive geometry, by analyzing a case study involving $10^{\text {th }}$ grade students. We develop Duval's work on visualization and deconstructions to make it fully operational in this context, especially by refining the Instrumental Deconstruction notion. We use the cKc modeling framework (Balacheff, 2013) to analyze how construction tasks are fundamental in this process. Our intention is to

\footnotetext{
1 Joris Mithalal, Université de Lyon; Université Claude Bernard Lyon 1; S2HEP (EA4148) Bâtiment "La Pagode", 38 Boulevard Niels Bohr - Campus de la DOUA Université Claude Bernard Lyon 1 - 43, Boulevard du 11 Novembre 1918 69622 Villeurbanne Cedex joris.mithalal@univ-lyon1.fr

2 Nicolas Balacheff, Laboratoire d'Informatique de Grenoble Univ. Grenoble Alpes, CNRS, Grenoble INP, LIG, F-38000 Grenoble France nicolas.balacheff@imag.fr
} 
show that it is possible to create strong and productive links between manipulation and deduction by using construction tasks in 3D DGEs.

We first focus on the role of drawings in geometry and the skills students have to master when doing deductive geometry. In this way, 3D geometry tasks with DGEs are promising. The second section is dedicated to show that, contrary to some previous assumption (Duval, 2005), the learning of these skills can be done continuously, and that Instrumental Deconstruction plays a pivotal role. Then, to understand this role, we refine this notion and show that two types of Instrumental Deconstruction are involved in the learning of geometry.

\section{WORKING WITH DRAWINGS IN GEOMETRY}

\subsection{GEOMETRICAL OBJECTS, FIGURES AND DRAWINGS}

The drawing problem is multifaceted:

"Diagrams in two-dimensional geometry play an ambiguous role: on the one hand, they refer to theoretical geometrical properties, while on the other, they offer spatio-graphical properties that can give rise to a student's perceptual activity. Students often conclude that it is possible to construct a geometrical diagram using only visual cues, or to deduce a property empirically by checking the diagram. When students are asked by a teacher to construct a diagram, the teacher expects them to work at the level of geometry using theoretical knowledge, whereas students often stay at a graphical level and try only to satisfy the visual constraints." (Laborde, 2004, p. 2).

However, a strict opposition between manipulation of drawings and abstract reasoning would be too simplistic. As Parzysz (1988) noted, students' activity in geometry involves "seeing" as well as "knowing"; it is a mix of observation and deduction.

Research on the learning of geometry raises the question of understanding the nature of geometrical objects and of the role they play in discussing and establishing the validity of a statement. At the core of this question is the "double nature" - figural and conceptual - of geometrical objects which led Fischbein (1993, pp. 148-149) to coin the notion of figural concept emphasizing the close link in geometry between ideal objects and their concrete representations. But, as Fischbein noted, the use of the word "figure" is ambiguous. He himself chose to denote by the expression "geometrical figure" the mental image "the properties of which are completely controlled by a definition" (ibid.). Because we will not explore mental images, we will adopt in this article the distinction made by Laborde and Capponi (1994, pp. 168-169), between drawings and figures which extends Fischbein's choice and will facilitate our analysis. Following Laborde and Capponi, a figure is the association of a theoretical referent defined by the conjunction of geometrical properties, the geometrical object, and a set of drawings, its representations. Hence a drawing can be considered for itself, as a graphical object, or as one of the possible representation of a geometrical object. Then, solving geometry problems is neither purely experimental nor purely deductive, but it involves going back and forth between both (Parzysz, 2006, p. 128). 
Studying the role of drawings as constraints in the learning of geometry, Chaachoua (1997) distinguishes two functions:

1. An illustration function: Drawings can illustrate the problem's statements, eliciting hypothesis, or can point to elements which could be relevant for the resolution. (ibid.p. 32-34)

2. An experimentation function: drawings provide a field where a large part of the resolution is caried out, experimentally. Working on drawings involves identifying new sub-figures or relations, making or testing conjectures, etc. This use of drawings is specific to the heuristic phase of the problem solving process. (ibid p.35)

Chaachoua (1997, pp.42-45) showed that to students' eyes, drawings could either represent nothing but themselves, represent another material object, or stand for a geometrical object (considered conceptually). In the latter case, they are only means supporting geometrical activities. Duval (2005) makes it more precise, explaining that there are two modalities of visualization which guide the exploration and the interpretation ${ }^{3}$ of a drawing: the iconic and the non-iconic.

Iconic Visualization is the most spontaneous approach to a drawing; it means that one recognizes an object because its shape is similar to an already known object. This is why some students identify a square as a rhombus, but not as a square (Fig. 1). They cannot, as well, modify or analyze a drawing: adding lines changes the appearance, and hence the nature of the related object. Duval (2005) shows that as this is the usual way of visualizing, pupils tend to keep working with Iconic Visualization. Chaachoua's work demonstrates that being able to use nothing but this kind of visualization is an obstacle to mobilizing deductive geometry, as it involves experimental work and analytic study of the drawings.
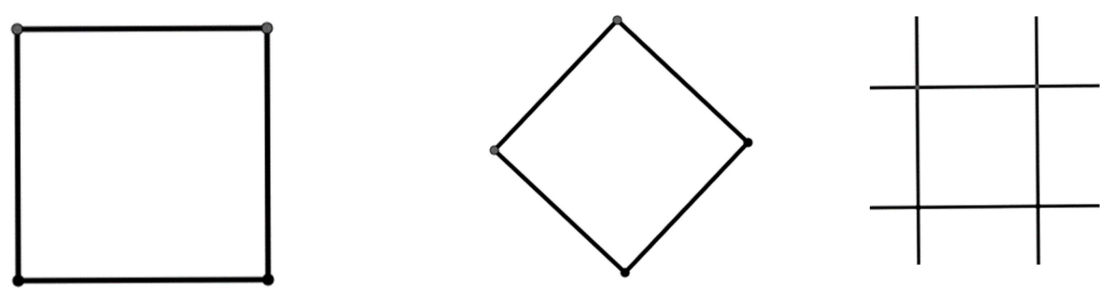

Figure 1: A square, a rhombus and "something from a square" (Iconic Visualization)

To Non-Iconic Visualization, a drawing is nothing but one of the representations of a geometrical object. Shape and appearance are no longer fundamental characteristics, as the drawing is seen as the assembly of lower dimension components, the figural units (points, lines, segments, circles). Therefore, there is no contradiction between modifying a drawing and considering that it remains a representation of the same object. But passing from Iconic Visualization to Non-Iconic Visualization is neither easy nor natural. Duval (2005, pp. 45-48) stresses that going from high dimension objects to lowers components is the most common spontaneous way of visualization, whereas identifying first inner components in order to recompose bigger ones is specific to mathematics and needs training. This dimensional hiatus is an important obstacle to the learning of deductive geometry.

3 In this case, seeing means both perceiving and interpreting what is perceived. We will keep this meaning for "visualization". 


\subsection{THE ROLE OF VISUALIZATIONS AND DECONSTRUCTIONS}

Duval (2005, pp. 16-17) explains that using drawings in order to solve geometry problems involves three distinct operations: Mereological Deconstruction, Instrumental Deconstruction and Dimensional Deconstruction. We will not use the first type which corresponds to "heuristic breaking down of the shapes" (Laborde, Mithalal, \& Restrepo, 2009 , p. 5), but focus on the two others which relate drawing and discourse:

- Instrumental Deconstruction answers the question "How is it possible to produce this drawing with a given set of tools?". A drawing is considered as the result of a construction process associated with a geometrical object. For instance, an Instrumental Deconstruction of a rhombus could be: "construct a segment [AC], the perpendicular bisector of this segment, $B$ and $D$ belonging to this perpendicular bisector so that $A B=A D$ ". Properties of the object may appear more "mechanical" than "geometrical".

- Dimensional Deconstruction is a discursive interpretation: a figure is considered as a set of figural units linked by a set of geometrical properties, and the drawing is analyzed accordingly. A rhombus is now "four distinct points $A, B, C, D$, with $A B=B C=C D=D A^{\prime \prime}$. This does not refer to a process, but it is based on the properties of the geometrical object; discourse is the main representation of the geometrical object.

We can notice a connection with the "drawing" ${ }^{4}$ Vs "constructing" distinction (Healy, Hoelzl, Hoyles, \& Noss, 1994). Iconic Visualization-based strategies focus on the shape and its perceived features; it guides the production of a drawing which "looks" right. Dimensional Deconstruction requires a theoretical approach and the use of geometrical properties; the interpretation it provides of the graphical objects may lead to a "constructing" characterization - no matter the size or the orientation, the important point is that the figure cannot be "messed up". Nevertheless, the deconstructions are not about effective processes students perform, but about the mechanism involved in their treatments of the drawings. Therefore, Instrumental Deconstruction can be either dedicated to reproducing a given shape - and in this case it is close to the drawing process -, or to using mechanical properties linked to instruments, in which case it is close to the constructing process.

Visualization and deconstructions differ in nature but have strong links. Visualization deals with the perception of drawings. Deconstructions are processes involved in their analysis. Dimensional Deconstruction connects drawings to geometrical objects, hence bridging the gap between drawing and proving, while Instrumental Deconstruction lays the ground for the problem-solving process. Non-Iconic Visualization is a necessary condition for Dimensional Deconstruction to be operational, which itself is an unavoidable tool to engage in deductive geometry and the construction of intellectual proofs ${ }^{5}$.

Duval $(1994,2005)$ claims that the transition from the geometry of drawings to the geometry of figures, which is necessary to the learning of mathematical proof in geometry, requires the double transition from Iconic Visualization to Non-iconic Visualization, and from Instrumental Deconstruction to Dimensional deconstruction.

\footnotetext{
${ }^{4} \mathrm{~A}$ reviewer drew our attention to the fact that "in the United States, with DGS, "draw" means to make a figure that "looks right". "Construct" means to make a figure that is right due to how it is constructed and hence cannot be "messed up"." In this article, we use "draw" to denote the production of a drawing in whatever way (sketching or constructing), and we use "construct" for the production of a drawing carefully using instruments and/or knowledge with the intention to be right (but sometimes being wrong).

${ }^{5}$ By "intellectual proofs" we mean "[proofs] which use verbalizations of the properties of objects and of their relationships [...] it requires a genuine construction of language means as an operative tool. The problem-solver must be able to use language and symbols as means to compute on statements and relations." (Balacheff, 1988, p. 285)
} 
Duval $(1994,1999,2005)$ considers that the two deconstructions are distinct processes: each has to be taught separately with specialized activities. On the contrary, the case study we report in this paper will demonstrate that it is possible to bridge the gap between both, and to make Instrumental Deconstruction and Dimensional Deconstruction the two sides of a single problem-solving process. We will show that students can be led to using Non-Iconic Visualization because of the failure of Iconic Visualization, and that analyzing the role of the artifacts helps to understand why Instrumental Deconstruction and Dimensional Deconstruction can be strongly linked. In the remainder of this paper, section 2 will be dedicated to show the continuum between both deconstructions, and section 3 to refine the notion of Instrumental Deconstruction.

\subsection{USING 3D-GEOMETRY: WHY, WHAT FOR, HOW?}

Two dimensional (2D) representations of 3D geometrical objects raise several visualization issues. First, it is no longer possible to confuse the representation with the object itself. Secondly, one cannot rely confidently on the visual information, as perception can be misleading. Then, the analysis of the relation between the representation and the associated object necessarily involves reconstructing the latter using properties of low dimensions units (e.g. lines, points) of the former. These issues make Iconic Visualization insufficient for 3D geometrical problem solving, opening the possibility for Non-Iconic Visualization to emerge as a way of restoring the capability of perceiving reliable information. This emergence is very complicated in a paper-and-pencil environment. However, the access to 3D geometry can be facilitated by the use of DGEs which allow the representation and the direct manipulation of 3D geometrical objects (Chaachoua, 1997, p. 265). We have chosen Cabri 3D ${ }^{6}$ which has such characteristics, allowing the construction and the manipulation of drawings simulating 3D geometrical objects.

\subsubsection{DRAWINGS AND TOOLS IN CABRI 3D}

Cabri3D drawings are images on a computer screen simulating 3D geometrical objects, which means that it is possible to manipulate what appears first as a 2D representation but which behaves when manipulated with properties evoking the third dimension. The user can continuously change the point of view of the objects by manipulating one of its component. The third dimension is simulated by a "fog effect" that makes objects progressively fade away while they are increasingly distant. As a screen is flat, moving a point in space has been split in two operations: in a plane parallel to $(x O y)$ with constant $z$ coordinate, or following a parallel to the $(\mathrm{Oz})$ axis. The combination of various views of the same object allows the user to detect misleading perceptions of the 2D representation and lowers the risk of attributing some wrong properties to the geometrical object (fig.2).
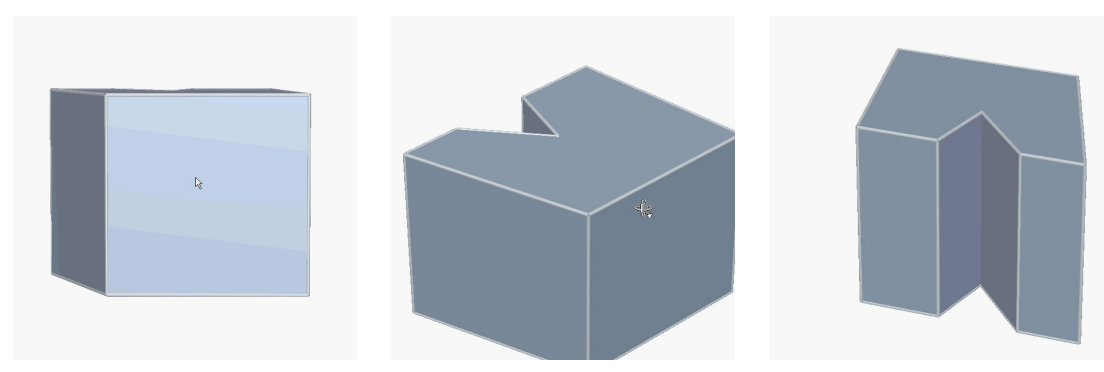

Figure 2: Moving a drawing to get more reliable visual information

\footnotetext{
${ }^{6}$ Cabri 3D is a Cabrilog software. More information available here: https://cabri.com/fr/cabri3d/
} 
Following the design principles of DGEs, a drawing keeps the properties underlining the geometric properties used to produce it when any of its free point is moved on the surface of the screen.

\section{CABRI 3D AS A MILIEU TO STIMULATE GEOMETRICAL REASONING}

DGEs, as geometrical computer-based environments whose design principle is the direct manipulation of the representations of geometrical objects, share common characteristics but also differ in many ways either in by the choice of the functionalities or the look and feel of the interface. Hence we will use the concept of milieu ${ }^{7}$ of the Theory of didactical situations (Brousseau, 1997, pp. 226-249) in order to indicate our focus on one key feature that these environments have in common: the nature of the feedback they provide following the direct manipulation of base elements of a representation (Laborde, 1993). Every DGE allows dragging points and modifying a drawing with respect to the geometrical properties underpinning its construction; this construction is then pragmatically valid when it cannot be messed up (Healy et al., 1994; Laborde, 1993). This characteristic makes DGEs relevant environments to set a milieu for teaching figures (Laborde, 2000; Laborde \& Capponi, 1994) and introducting the dialectic of conjecturing and proving (Baccaglini-Frank \& Mariotti, 2010).

This study reported here has been carried out as part of the scientific programme of the Cabri-geometry research group; it used the Cabri3D DGE.

Cabri3D makes it possible to design elementary construction tasks, not requiring at first high geometrical knowledge. However, any user soon realizes that mere perception is not sufficient in order to get reliable information. For instance, it is hardly possible to construct a cube-looking polyhedron only by adjusting the position of the points, whereas it is very easy to construct a square-like polygon using this strategy in a 2D DGE. Since visual information is not sufficient to ensure the correctness of constructions or to get information, geometrical knowledge and geometrical reasoning are necessary. The complexity and the fundamental character of the dragging process (Hatterman, 2008) should favour the move towards both Non-inconic visualization and Dimensional deconstruction, hence stimulating the transition to geometrical reasoning and intellectual proof. This is what we will illustrate and analyze in the remaining of this article.

\section{BRIDGING THE GAP BETWEEN THE TWO DECONSTRUCTIONS: A CASE STUDY}

The following case study aims at describing the continuum between Iconic and Non-Iconic Visualization. We examine the role of Instrumental Deconstruction in this change of the visualization process, and how it eventually provokes the use of Dimensional Deconstruction. We use the data gathered from an experiment detailed in Mithalal (2010) ${ }^{8}$.

\footnotetext{
7 The concept of "milieu", from the Theory of Didactical Situation, refers to the "system opposing the taught system" (Brousseau, 1997, p. 57). In other words it is this part of the environment wich is meaningful from the perspective of the learning stake by the kind of feedback it provides to the student. "That is to say that the student's answer must not be motivated by obligations related to the didactical contract but by adidactical necessities of her relationships to the milieu" (ibid.).

8 The experiment was carried out in French classes, so the transcripts in this article are our own translation. For the French original transcripts, see Mithalal (2010).
} 


\subsection{CONTEXT OF THE STUDY}

The experiment was carried out with four classes of French $10^{\text {th }}$ grade students, working by pairs on Cabri3D activities. These students had a limited experience with 3D geometry and elementary shapes. A first one hour session was dedicated to learning how to use Cabri 3D, and the second which we analyze here, was a construction activity. Our analysis is based on the records of each pair of students' voices and on their activity by video recording the screens, transcribed afterwards.

The task was the following:

Let $A B C D E H G F_{1} F_{2} F_{3}$ be a truncated cube (Fig. 3). Find as many ways as possible to construct the missing vertex ${ }^{9}$, and describe each method in a few words.

The point A can be manipulated. Even after the little training they had received, the constraint on whatever solution they came up with was clear to students: the cube they obtain by constructing the missing vertex must remain a cube whenever dragging $A$.

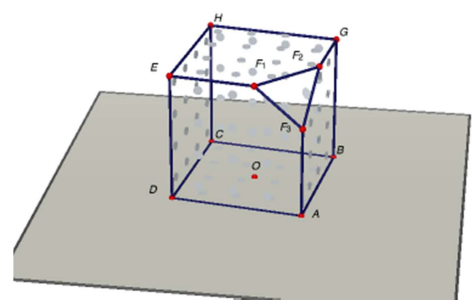

Figure 3: The truncated cube students had to complete

With such a task, Iconic Visualization would lead to accept the construction of the missing part of the shape without considering geometrical properties, but it will be immediately messed up by dragging the point $A$. On the contrary Non-Iconic Visualization could lead to use the cube properties (such as symmetry) to construct $F$, hence meeting the DGE basic criterion which is to get a robust result when manipulating free points. On the basis of an $a$ priori analysis, four distinct interpretations corresponding to specific resolution strategies were identified (Mithalal, 2010, p. 149):

1. To draw the missing part so that the result looks like a cube;

2. To draw the missing part so that the result looks like a cube and keeps the same measures as the original;

3. To draw a point using a construction procedure that fits with a cube;

4. To construct a point linked to the truncated cube with its geometrical properties.

9 In French vertex is "sommet", which has not only a mathematical meaning but also a meaning in everyday language, namely, "summit". 


\subsection{Connecting ICONIC to Non-ICONIC Visualization AND InStRUmental to Dimensional}

\section{DECONSTRUCTION}

This subsection aims at showing the differences between visually controlled drawing (corresponding to Iconic Visualization), Instrumental and Dimensional Deconstructions, and to analyze their potential relations. For this purpose, we will use excerpts of full transcripts available in Mithalal (2010). We will give only a partial account of the students' exchanges and indicate their timing in order to alert us that these are not continuous dialogs, but illustrating sentences. This data has been analyzed in Mithalal (2010), identifying precisely the pupil's strategies and the related conceptions. We will describe the evolution of these conceptions during the solving process by using the excerpts to illustrate the identified evolution.

\subsubsection{FROM ICONIC TO NON-ICONIC VISUALIZATION}

Even when a solution is based on Iconic Visualization, as it is illustrated by the case of Ludovic and Pierre quoted below, students may use Cabri3D geometrical tools in an attempt to lower the randomness of the action they performed (Mithalal, 2010, p. 163).

Pierre and Ludovic tried to construct the shape relying on a visual monitoring of their action on the screen. They spent about 25 minutes trying to locate the right place of a point. They concluded after unsuccessful trials that is was impossible, and decided that they needed another method:

16'06, Ludovic: Anyway, we can't see anything.

21'57, Pierre: It looks good, and when it moves, it looks like nothing...

26'22, Pierre: We have to find another solution.

Their aim remained that "it looks good", but they realized that the means for it had to be improved. They then tried various methods, including intersecting the three truncated edges (two would have been enough), constructing parallels, or using vectors (they failed).

The dominant approach, determined by Iconic Visualization, was to try first to complete the shape. But the failure of this approach pushed students to use the construction tools of Cabri 3D. To do so they needed to break the cube down in order to identify figural units, hence switching to Instrumental Deconstruction. Iconic Visualization and Instrumental Deconstruction worked together for two distinct but complementary purposes, the former providing perceptual assessment of the outcomes of the latter. As a consequence, the students moved step-by-step to Non-Iconic Visualization.

\subsubsection{Connecting Instrumental to Dimensional DeCONStruction}

The central place of construction tools and direct manipulation could orient the students activity towards Instrumental Deconstruction, thanks to what could be described as a mechanical conception of the DGE. However, as the tools made available by such a software can be read as reification of geometry primitives, Dimensional Deconstruction could prove useful for anticipating the strategies and their validity, and grounding argumentation.

This is illustrated by the case of Marie, Paul and Julie. These students first decided that "reconstructing the cube" was not sufficient and that they had to draw the missing part.

13'19, Paul: Maybe we should try with a point, just a point here, at the right place.

13'24, Marie: But in this case you leave it to chance!

13'27, Paul: No! I mean, yes! Well, you make it... 
Their problem was to be sure that the construction was correct, and they eventually decided that it was "approximately good", which was enough for them. Marie's objection was about the ways of controlling the position of $F$, so they decided to use constructing functionalities of the software, such as edges intersections or symmetry. During half an hour, the correctness remained determined by the visual aspect of the shape (Iconic Visualization) and the robustness when moving free points (Instrumental Deconstruction).Then they succeeded in constructing $\mathrm{F}$ by intersecting 3 edges (Fig. 4, left picture).

Later, they tried another solution by constructing a figure symmetric to the truncated cube, and using it to construct lines (Fig. 4, $2^{\text {nd }} \& 3^{\text {rd }}$ pictures). Deciding whether this last method was really new or not, turned to be a Dimensional Deconstruction problem:

25'46, Julie: Look, you construct the same ${ }^{10}$ next to it. You'll see, the shape will do schlack, schlack, you see it will be a rhombus. Then, you use from this one to that one. To its symmetric. Then, you only have to do this,... Then you create the line, and you make it. ${ }^{11}$

31'50, Marie: Wait, wait, because I just thought about it: the [second] cube is absolutely useless...

32'14, Pierre: Yes, in fact you just did the same $!^{12}$

32'15, Marie: Exactly. That's it: you just added a cube on the two sides.

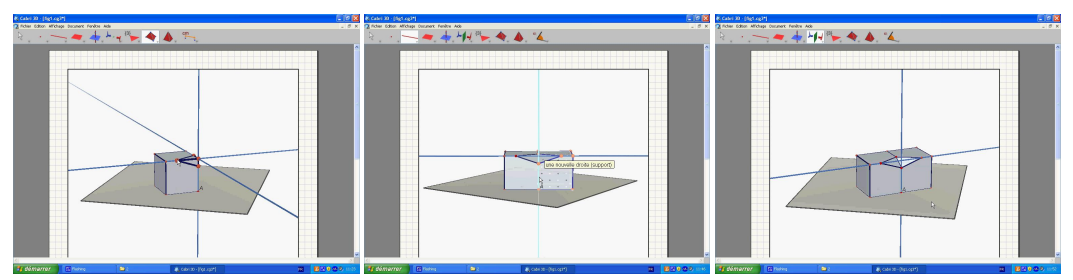

Figure 4: Construction with three lines or with the symmetrical of the cube.

The result was visually different from the former one, and so was the construction process although they used the same lines. The students decided that this solution was identical to the previous one (Fig. 4, left picture), not because of the shape or the construction process, but because they used the same lines. Thus, their interpretation of the strategies turned to be based on Dimensional Deconstruction. This shows how Instrumental Deconstruction and Dimensional Deconstruction can be strongly linked. Dimensional Deconstruction facilitates the design of the construction process and evaluating its validity. Instrumental Deconstruction problems make Dimensional Deconstruction (hence geometrical knowledge) play a greater role.

\footnotetext{
10 The same truncated cube, symmetrical to the original one with respect to $(A B C)$

11 Julie described how to construct $F$ as an intersection of two lines.

12 The same as the previous method, which was the intersection of two edges
} 


\subsubsection{The Pivotal ROLE OF InStrumental DeCONSTRUCtion}

These examples illustrate the two main reasons for the evolution of the students' activity:

- $\quad$ First, students look for more reliable ways to act and for more efficient visual monitoring.

- $\quad$ Second, they need to better anticipate and manage their actions.

In the first case Instrumental Deconstruction renders reliable and efficient an approach initially based on Iconic Visualization. Then, Instrumental Deconstruction turns to be the operational side of the Dimensional Deconstruction, which itself provides the needed geometrical grounds required to justify the construction process. It .strongly modifies the way problems are addressed, becoming more theoretical, which makes deductive geometry meaningful.

Nevertheless, such evolutions are difficult to describe and to analyze because the data related to these two roles of the Instrumental Deconstructions are similar. The same processes might be used with different purposes, and a similar aim may generate different strategies. To get a more accurate view, we used the cKc model which accounts for the tight relationship between operators, instantiated by students' actions which are observed, and the associated controls which motivate or justify their use.

\section{INSTRUMENTAL DECONSTRUCTIONS}

In order to understand how small variations of the students' means may indicate greater evolution of their purpose, we will highlight here two kinds of Instrumental Deconstructions. For this we will use the cKc modeling framework to analyse data in a precise way, relating action and control along a problem solving process in relation to the students conceptions. The following section introduces shortly the cKc framework.

\subsection{CONDITIONAL ACTION VERSUS CONTROL}

The cKC modeling framework (Balacheff, 2013) is based on the Theory of Conceptual Fields (Vergnaud, 2009) and on the Theory of Didactical Situations (Brousseau, 1997). This model accepts the postulate shared by these theories stating that the first aspect characterizing a piece of mathematical knowledge is the set of problems it allows to solve. This set directs the students conceptions and grounds their legitimacy. This situated nature of ways of knowing in mathematics is recognized since the seminal work of Vinner (1983), and Confrey (1990). Their critical analysis of the research on misconceptions led to the adoption of the generic term "conception" (ibid. p.29). In this context, the $\mathrm{CK} C$ model considers a conception not as a student's characteristic, but as a property of the interacting system formed by the student and a milieu with which he or she is acting and interacting (Balacheff, 2013, p. 6). It characterizes it by the conjunction of four elements: its domain of validity (a set of problems), the representation system it mobilized (possibly blending several semiotic systems), the set of operators which are available to contribute to solving problems, and the control structure which provide means to make choices, assess feedback, take decisions, and judge the advancement of a problem solving process.

We focus for this case-study on the interactions between operators and controls, considering that the dimension of the representation system, which consists of a combination of natural language and Cabri 3D representations and associated tools, is common to all observed pair of students. The identification of operators and controls is based on a close analysis of the students discourse, identifying the utterances and their evolution, and the related actions at the interface of the DGE ${ }^{13}$. An issue when performing this analysis is that some controls and operators may look

\footnotetext{
${ }^{13}$ For a complete presentation of the $\mathrm{CKC}$ model, the reader is invited to refer to Mithalal (2010, Appendix pp. 11-26).
} 
the same (Pedemonte \& Balacheff, 2016, p. 121). For instance, "the symmetrical image of a segment $\mathrm{S}_{1}$ is a segment $\mathrm{S}_{2}$ whose extremities are symmetrical to the extremities of the segment $\mathrm{S}_{1}$ " could work either as an operator (To construct $\left[A^{\prime} B^{\prime}\right]=S y m_{d}([A B])$, link $A^{\prime}=S y m_{d}(A)$ to $B^{\prime}=S y m_{d}(B)$ ) or as a control (The symmetrical image of a segment is another segment whose extremities are symmetrical to the extremities of the initial one). This correspond to the dual nature, operational versus predicative, of knowledge pointed by Vergnaud (2009). In order to decide which of the two meanings to consider for a single utterance, we took the following criterion: if, based on the observed behavior and recorded discourse, an utterance could be represented by a formula of the form: [Statement ${ }_{1} \Rightarrow$ Action] we classified it as an operator, but we classified it as a control if it could be represented by a formula of the form: [Statement ${ }_{1} \Rightarrow$ Statement $_{2}$ ]. Indeed, operators are easier to identify because of their observable materialization as behaviors often associated to discourse, and explicit interaction with the milieu whereas controls are often left implicit. However a well designed experiment involving social interaction facilitates their identification as they are more likely to be made explicit during the verbal communication between students as to their reasons for their choices and decisions.

Controls play different roles at different phases of the problem-solving process:

(1) In an initial phase, controls determine the type of problem, a set of possibly adequate operators (a selection function (Vadcard, 2000)), and a priori reasons for the relevance of a strategy.

(2) During the resolution phase of the problem, referent controls "regulate the anticipation of the action and the adequacy between the expectations and the results" (Gaudin, 2005, p. 153).

(3) In a final phase, controls provide a posteriori assessment of the validity of a solution.

The analysis of phase (2) requires a special attention in order to distinguish operators from controls. During this phase controls provide information about the coherence of an approach and its possible evolution. Phases (1) and (3) are more about how geometry problems are considered by students, and the level of proving they engage in. The analytical tool provided by $\mathrm{cKC}$ facilitated eliciting the way Instrumental and Dimensional Deconstructions shape the problem solving process and evolve as levels in the transition from pragmatic proofs (based on drawings) to intellectual proof.

\subsection{THE IMPORTANCE OF IDENTIFYING CONTROLS BEYOND THE OBSERVED BEHAVIORS}

In this section we show that identifying the Instrumental Deconstruction is insufficient to interpret the strategies of the students.

Let us go back to the case of Pierre and Ludovic. They constructed the lines from the truncated edges, then their intersection ${ }^{14}$, and filled in the cube so that "it looks like a cube". From a mathematical point of view, the three lines were useless but needed in order to complete the shape. Then Pierre and Ludovic added the three "missing" triangles, confirming their focus on the shape (Fig.5).

\footnotetext{
${ }^{14}$ Cabri3D provides the user with an "intersection" tool, that constructs the intersection of two objects. It is not obvious that it does not construct the intersection of the three lines, as it only displays a message saying "this intersection point".
} 


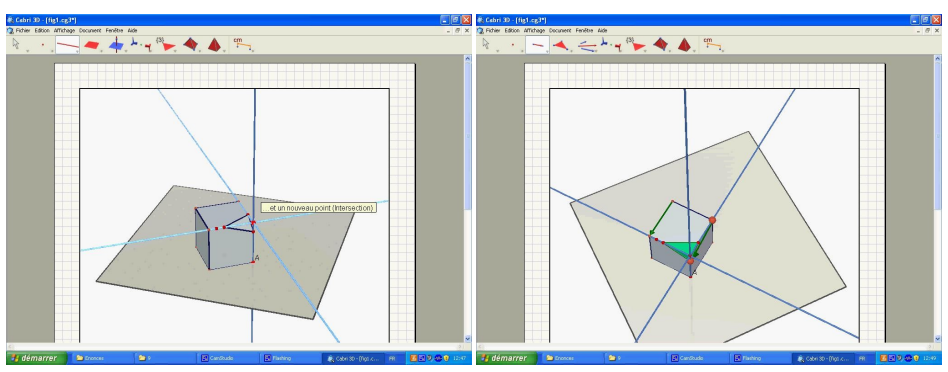

Figure 5: Trying to draw the missing part of the cube with 3 lines

Another group of students, Marie, Paul and Julie, followed the same construction process: construct the lines from the truncated edges, then the intersection. They engaged in this strategy at the very beginning:

3'11 [Marie created a straight line on a truncated edge.]

3'19, Paul: Tell me what you're doing!

3'20, Marie: You perfectly see what l'm doing.

3'22, Paul: Yes, you put a line, but explain us what you want to do.

3'23\&3'27 [Marie created the two other lines.]

3'28, Paul: Ok, and then?

3'30, Marie: And then, you think I'm stupid! Don't you see the cube is done?

Marie intended to draw the missing corner so it looked like a cube. Her interpretation and final control was: $\sigma_{\text {visual }}=$ [The aim is to construct an object $\Rightarrow$ The result has to look like the referent shape]. This control is related to a drawing process (Healy et al., 1994) which is typical of Iconic Visualization, as was Pierre and Ludovic's. Both groups used similar operators: $r_{\text {line }}=$ [construct a line on a segment $\Rightarrow$ select the 'straight line' tool and left-click on the segment] and $r_{\text {triangle }}=$ [construct a triangle $\Rightarrow$ select the 'triangle' tool and left click on the three vertices]. These operators do not require theoretical control, and can be performed purely visually. The key difference between these groups is that, in order to control the construction process, Pierre and Ludovic only used $\sigma_{\text {visual }}$ whereras Marie's work indicates that she could anticipate the validity of her construction. This anticipation was necessarily based on non-visual control backed by known geometrical properties, and then on Dimensional Deconstruction : $\sigma_{\mathrm{DD}}=$ [The aim is to construct an object $\Rightarrow$ The tools to be used are those corresponding to the objects' geometrical properties].

Even if the procedures and their outcomes are very similar, focusing on controls reveals significant differences: Marie, Paul and Julie considered that the exercise was about the shape, but they could use geometrical knowledge as tools for controlling their actions. On the other hand, Pierre and Ludovic failed when geometrical controls were needed. With the same aim to reproduce a shape, two Instrumental Deconstructions underpin processes differing in the nature of their associated controls, namely, (1) visual control (Iconic Visualization), (2) geometrical controls (Non-iconic Visualization).

\subsection{EVOLUtion OF THE INSTRUMENTAL DECONSTRUCTION}

As illustrated by the former cases, on the basis of the controls involved, it is possible to distinguish two types of Instrumental Deconstruction. The first one [Instrumental Deconstruction / Iconic Visualisation] involves shape-based controls, that is Iconic visualization, the other one [Instrumental Deconstruction / Non-Iconic Visualisation] is based on geometrical controls, that is Non-Iconic Visualization. Of course, these are types and for instance we may consider in the above examples, that Pierre and Ludovic used [Instrumental Deconstruction / Iconic Visualisation] but that Marie was midway between the two types. 
The identification of these types of controls provides good indicators of the evolutions of the student's activity, and of the way they may move towards Dimensional Deconstruction. Let us go back to the case of Pierre and Ludovic, decomposing it into successive strategies.

\section{Initial strategy}

The first objective of Ludovic was to draw the missing vertex of the cube by creating a point and dragging it at the right position. To do so he could use the operator $r=$ [create a point $\Rightarrow$ select the 'point' tool and left-click on the screen]. The point was then dragged at the right place, using visual control. This strategy was based on Iconic Visualization, and the a priori referent and the a posteriori controls were identical $\left(\sigma_{\text {visual }}\right)$. Ludovic used another control $\sigma_{\text {point of view }}=$ [The aim is to construct an object $\Rightarrow$ The result has to look like the referent shape when changing the viewpoint]. This control is close to $\sigma_{\text {visual, }}$ and it is still based on Iconic Visualization, but it is a good way to get more reliable information on the results. This information made them realize that the shape was not correct ("It looks good, and when it moves, it looks like nothing...") and they had to find another strategy to draw the shape correctly.

\section{Borrowed strategy}

The new strategy was borrowed from other students (27'25: "We'll do the same as they do! Look at their solution!)". The successful construction they saw on the screen of the other students was enough for them to justify their new strategy, constructing lines and intersections $\left(r_{\text {line }}\right.$ and $r_{\text {intersection }}=$ [construct an intersection point of two lines $\Rightarrow$ select the 'point' tool and left-click on the lines intersection]). It was carried out step by step, using the Cabri3D tools so that the result looked like a cube; the initial and final controls were still visual.

\section{Alternative strategies}

In search for another strategy, they kept the objective of constructing an intersection point of lines based on the truncated edges, but with different Cabri-tools than for the borrowed strategy. To do so, they tried the parallel tool: $r_{\text {parallel }}=$ [construct line on a truncated edge, parallel to another edge $\Rightarrow$ select the 'parallel' tool, left-click on the edge giving the direction, and on the truncated edge]. Even if visual control was still possible, this operator required a control based on geometrical properties of the cube: $\sigma_{\text {cube edges }}=$ [The aim is to construct a line on a truncated edge $\Rightarrow$ This line is parallel to other edges]. This control needs the identification of figural units and geometrical properties, hence a move towards a Dimensional Deconstruction which required a Non-iconic Visualization.

To succeed in the task based on [Instrumental Deconstruction / Iconic Visualisation], visual control was fundamental for Pierre and Ludovic, and was supported by the use of Cabri3D's tools. This control didn't allow them to succeed, and the DGE feedback gave evidence to their failure hence made them look for more reliable strategies. These strategies were based on geometrical tools which could be controlled with $\sigma_{\text {visual }}$ at the graphical interface of the DGE. Pierre and Ludovic tried to use the tetrahedron tool and, again, the feedback showed them that they were wrong. They failed again trying to use vectors, but were more successful using "line on segment" or "parallel" which were easier to control, possibly due to better knowledge and visual feedback. They gradually used more and more complex geometrical tools, and in this way the Instrumental Deconstruction evolved. At the beginning, it was based on experimental trials and error and required $\sigma_{\text {visual }}$. Step by step, they started to take into account relations between figural units (for instance with $\sigma_{\text {cube edges }}$ ), some of them being visible (intersections), others not (vectors). This was a first step towards Non-Iconic Visualization, and some of the referent controls were based on Dimensional Deconstruction. Nevertheless, as they couldn't use any other control but visualization, they failed when trying to use more elaborated strategies. 
This evolution lasted one hour, and we cannot assume it to be a stable evolution. Nevertheless, this identification of operators and controls brings out the progression from [Instrumental Deconstruction / Iconic Visualisation] to [Instrumental Deconstruction / Non-Iconic Visualisation] which appears to be, at the same time, both complex and a key to students move from drawings to figures.

\section{Discussion}

Our aim in this article was to clarify the relations between Iconic Visualization and Non-iconic Visualization, between Instrumental Deconstruction and Dimensional Deconstruction. We also tried to understand how constructions tasks in a 3D DGE, by creating an "intellectual need" (Harel, 2008, p. 488), may stimulate students' move from drawings to figures which is an essential step towards mathematical proving. To do so, we had to refine methodological and theoretical tools.

Following Duval's (2005) work, we recognize that perception plays a key role in the mathematical work of the students. However, in order to connect the working on the drawings to identifying or representing geometrical properties, the students must be able to perform specific operations, Instrumental Deconstructions and Dimensional Deconstructions, that require a change in perception and the use of Non-Iconic Visualization.

Duval (2005, pp. 19-20) considered that these two deconstructions are too different to be connected. On the contrary, our case study shows that it is possible for students to move towards Dimensional Deconstruction, and at the same time towards Non-Iconic Visualization, by a specific use of Instrumental Deconstruction.

Based on a 3D DGE, the task we designed played a crucial role in this process. It rendered visual information less reliable, and then disqualified Iconic Visualization. The direct manipulation features of the DGE facilitates working on the drawings with empirical strategies, but the reproduction task design makes it inefficient. Finally, the DGE tools based on geometrical properties shed light on the figural units and their relations, so that the Instrumental Deconstruction comes to be strongly linked to the geometrical objects. This transition opens the possibility of a move from pragmatic proofs to intellectual proofs, which remains to be confirmed by specific research.

As a preliminary work, we had to characterize more precisely the way students' work changed. We used the cKc modeling framework to refine the analysis by distinguishing the evolution of the operators and controls involved. Our case study showed that it is possible for the pupils to use more efficient operators, without a fundamental change of the control system. On the other hand, such a change has to be interpreted carefully, as very similar construction processes may mean very different things about the student's ability to engage in Dimensional Deconstruction. It therefore makes sense to distinguish two types of Instrumental Deconstruction, the first one more related to Iconic Visualization, the second one to Non-Iconic Visualization. This allows to theoretically consider the possibility of a continuous evolution between the two kinds of visualization.

In conclusion, this case study shows that it is possible to design specific tasks to provoke the need for intellectual proof. The construction tasks we used, based on a 3D DGE, provided opportunities to facilitate the gradual transition of students' focus from drawings to figures, which have direct consequences for the teaching of mathematical proof. As in this case Iconic Visualisation was no longer reliable, there was an intellectual need for ways of controling actions independently from sight, in order not to "leave it to chance" (Marie, p.10). The evolution from [Instrumental Deconstruction / Iconic Visualisation] to [Instrumental Deconstruction / Non-Iconic Visualisation] was a response to the problem raised by the milieu: how is it possible to be confident in a given construction process? A priori theoretical control of the constructions came to be needed. 
Once they changed their construction process control, students also changed their interpretation of what "a new strategy" could be, now based on dimensional deconstruction (see p.8). There were no practical reasons to do so, as this could have been based on the construction process, but the situation raised an "intellectual need [...] inextricably linked to another notion: epistemological justification" (Harel, 2008, p. 488). In this way, such a task raises the need for intellectual proof. It made its subsequent teaching and learning required and meaningful.

\section{References}

Baccaglini-Frank, A., \& Mariotti, M. A. (2010). Generating Conjectures in Dynamic Geometry: The Maintaining Dragging Model. International Journal of Computers for Mathematical Learning, 15(3), 225-253.

Balacheff, N. (1988). A study of students' proving processes at the junior high school level. In I. Wirszup \& R. Streit (Eds.), Second UCSMP international conference on mathematics education (pp. 284-297). Chicago, United States: NCTM.

Balacheff, N. (2013). cKC, a model to reason on learners' conceptions. In M. V. Martinez \& A. Castro (Eds.), Proceedings of the 35th annual meeting of the North American Chapter of the International Group for the Psychology of Mathematics Education (PME-NA) (pp. 2-15). Chicago, IL, États-Unis.

Brousseau, G. (1997). Theory of Didactical Situations. (N. Balacheff, M. Cooper, R. Sutherland, \& V. Warfield, Trans.). Dordrecht: Kluwer Academic publishers.

Chaachoua, H. (1997). Fonctions du dessin dans l'enseignement de la géométrie dans l'espace. Etude d'un cas : la vie des problèmes de construction et rapports des enseignants à ces problèmes (PhD Thesis). Université Joseph Fourier, Grenoble, France.

Confrey, J. (1990). A Review of the Research on Student Conceptions in Mathematics, Science, and Programming. In C. Courtney (Ed.), Review of Research in Education (American Educational Research Association, Vol. 16, pp. 3-56).

Duval, R. (1994). Les différents fonctionnements d'une figure dans une démarche géométrique. Repères IREM, 17, 121-138.

Duval, R. (1999). Representation, vision and visualization: cognitive functions in mathematical thinking. Basic issues for learning. In Proceedings of the 21st Annual Meeting of the North American Chapter of the International Group for the Psychology of Mathematics Education (pp. 3-26). Cuernavaca, Morelos, Mexico.

Duval, R. (2005). Les conditions cognitives de l'apprentissage de la géométrie: développement de la visualisation, différenciation des raisonnements et coordination de leurs fonctionnements. Annales de Didactique et de Sciences Cognitives, 10, 5-53.

Fischbein, E. (1993). The theory of figural concepts. Educational Studies in Mathematics, 24(2), $139-162$.

Gaudin, N. (2005). Place de la validation dans la conceptualisation, le cas du concept de fonction (PhD Thesis). Université Joseph Fourier - Grenoble 1, Grenoble, France.

Harel, G. (2008). DNR perspective on mathematics curriculum and instruction, Part I: focus on proving. Zentralblatt Für Didaktik Der Mathematik, 40(3), 487-500. 
Hatterman, M. (2008). The dragging process in three dimensional dynamic geometry environments (DGE). In O. Figueras, J. L. Cortina, S. Alatorre, T. Rojano, \& A. Sepúlveda (Eds.), Proceedings of the Joint Meeting of PME 32 and PME-NA XXX (Vol. 32, pp. 129-136). Morelia, Mexico.

Healy, L., Hoelzl, R., Hoyles, C., \& Noss, R. (1994). Messing up. Micromath, 10(1), 14-17.

Jahnke, H. N. (2007). Proofs and hypotheses. ZDM, Zentralblatt Für Didaktik Der Mathematik, 1-2(39), 79-86.

Laborde, C. (1993). The Computer as Part of the Learning Environment: The Case of Geometry. In C. Keitel \& K. Ruthven (Eds.), Learning from Computers: Mathematics Education and Technology (Vol. 121, pp. 48-67). Berlin, Heidelberg: Springer.

Laborde, C. (2000). Dynamic geometry as a source of rich learning contexts for the complex activity of proving. Educational Studies in Mathematics, 44, 151-161.

Laborde, C. (2004). The Hidden Role of Diagrams in Students' Construction of Meaning in Geometry. In J. Kilpatrick, O. Skovsmose, \& P. Valero (Eds.), Meaning in mathematics education (Vol. 37, pp. 159-179). New York, NY: Springer.

Laborde, C., \& Capponi, B. (1994). Cabri-géomètre constituant d'un milieu pour l'apprentissage de la notion de figure géométrique. Recherches En Didactique Des Mathématiques, 14(1), 165-210.

Laborde, C., Mithalal, J., \& Restrepo, A. (2009). The use of tools in the learning and teaching of geometry. In National Council of Teachers of Mathematics, Research Presession, Washington DC.

Mithalal, J. (2010). Déconstruction instrumentale et déconstruction dimensionnelle dans le contexte de la géométrie dynamique tridimensionnelle (PhD Thesis). Université de Grenoble.

Parzysz, B. (1988). "Knowing" vs "Seeing", Problems of the plane representation of space geometry figures. Educational Studies in Mathematics, 19, 79-92.

Parzysz, B. (2006). La géométrie dans l'enseignement secondaire et en formation de professeurs des écoles : de quoi s'agit-il? Quaderni Di Ricerca in Didattica, 17, 121-144.

Pedemonte, B., \& Balacheff, N. (2016). Establishing links between conceptions, argumentation andproof through the ckc-enriched Toulmin model. The Journal of Mathematical Behavior, 104-122.

Vadcard, L. (2000). Étude de la notion d'angle sous le point de vue des conceptions (PhD Thesis). Université Joseph Fourier.

Vergnaud, G. (2009). The Theory of Conceptual Fields. Human Development, 52, 83-94.

Vinner, S. (1983). Concept definition, concept image and the notion of function. International Journal of Mathematical Education in Science and Technology, 14, 293-305. 